\title{
Effect of occupational therapy on self-determination skills of adolescents at risk of emotional and behavioral disorders: A randomized controlled trial
}

\author{
Elahe Hojati Abed ${ }^{1}$, Narges Shafaroodi ${ }^{1 *}$ (D), Malahat Akbarfahimi ${ }^{1}$, Armin Zareiyan $^{2}$, Akram Parand $^{3}$ \\ Received: 12 Jan 2020 \\ Published: 3 May 2021
}

\section{Abstract}

Background: Self-determination skills enable to support an individual's needs and make decisions to function independently. Improvement of self-determination skills has had a positive result for adolescents at risk of Emotional and Behavioral Disorders (EBD). The aim of this study was to investigate the effect of occupational therapy interventions on the self-determination skills of adolescent girls at risk of emotional-behavioral disorders.

Methods: In this single-blind control trial study, 14-16-years-old girl students ( $\mathrm{n}=54)$ at risk of EBD were recruited by cluster sampling from secondary high schools of Tehran, Iran. Youth self-report Questionnaire (YSR) was used to include adolescents at risk of EBD in the study and were randomized into the intervention $(n=27)$ and control group $(n=27)$ by block randomization. The Student SelfDetermination Scale (SDSS) and the Self-determination Parent Perception Scale (SDPPS) were used to collect data. Students in the intervention group participated in 8 - once a week- sessions of occupational therapy and the control group received no training. Data were analyzed by repeated-measures analysis of variance (RMANOVA), Bonferroni test and SPSS 16.0 version. The significance level was set at 0.05 .

Results: The score of self-determinations (SDSS) increased significantly in the intervention group after the intervention ( $<<0.001$ ). Although the mean scores of self-determination at follow-up have increased in the intervention group compared to the post-test. No significant differences were found $(\mathrm{p}>0.05)$; also, the score of parents' perception of student self-determination (SDPPS) increased but there were not significantly different $(\mathrm{p}=0.064)$.

Conclusion: The findings indicated self-determination skills could be taught to adolescents at risk of EBD in OT sessions. Since selfdetermination has been identified as the necessary skills for adolescents at-risk to transition into adulthood, occupational therapists have an important role in promoting self-determination skills in adolescents at risk of EBD.

Keywords: Occupational Therapy Interventions, Self-Determination, Emotional And Behavioral Disorders, Adolescents

Conflicts of Interest: None declared

Funding: Iran University of Medical Sciences

*This work has been published under CC BY-NC-SA 1.0 license.

Copyright $($ Iran University of Medical Sciences

Cite this article as: Hojati Abed E, Shafaroodi N, Akbarfahimi M, Zareiyan A, Parand A. Effect of occupational therapy on self-determination skills of adolescents at risk of emotional and behavioral disorders: A randomized controlled trial. Med J Islam Repub Iran. 2021 (3 May);35:57. https://doi.org/10.47176/mjiri.35.57

\section{Introduction}

Adolescence is a transitional stage in life with special

Corresponding author: Dr Narges Shafaroodi, shafarodi.n@iums.ac.ir

1. Department of Occupational Therapy, School of Rehabilitation Sciences, Iran University of Medical Sciences, Tehran, Iran

2. Department of Community Health, School of Nursing, AJA University of Medical Sciences, Tehran, Iran

3. School of Psychology, Tehran University, Tehran, Iran $\uparrow$ What is "already known" in this topic:

Self-determination knowledge and skills are important life skills for success throughout the transition from adolescence to adulthood. Students with emotional behavioral disorders (EBD) are at a low level of self-determination, so they need to gain training in this domain. As a result of, occupational therapists play a main role in transition services for adolescents by preparing occupation-based evaluation and intervention, but there is a gap in researches that occupational therapy can be an appropriate intervention to promote selfdetermination.

\section{$\rightarrow$ What this article adds:}

This study showed that the self-determination skills of EBD adolescents promote after occupational therapy sessions. Therefore, occupational therapy services can be used along with other educational services to strengthen the selfdetermination skills in high school settings for adolescents at risk of EBD. 
characteristics. Some of these characteristics play an important role in the health of adolescents into adulthood (1). During the adolescent period, a variety of emotional, physical, and social challenges are experienced which can have negative effects on behavioral adaptation (2). Studies indicated that approximately $20 \%$ of school-age population have emotional and behavioral disorders (EBD). Despite the prevalence of this disorder in the students, less than $1 \%$ of all students with EBD are supported (3). These students have higher absenteeism rates and lower academic achievement relative to comparison peers with other disabilities (4). They have problems with self-regulation and self-control and they also show deficits in areas vital for self-determination such as setting goals, delaying gratification, and having a precise self-appraisal $(5,6)$.

Self-determination defined as "voluntary actions that enables one to act as a key factor to gain control of and selfdirect their lives and to maintain or enhance the quality of life" (4), self-determination in disabled high school adolescents leads to positive results in education, work, leisure, independent living style, and quality of life (7-10). Thus, training programs in self-determination skills for youth with disabilities are important (11). Also, learning self-determination skills can help students with EBD make positive decisions as adults $(12,13)$. The model of self-determination developed by Field and Hoffman (1994) (14) emphasizes core concepts such as personal values, selfknowledge, and engagement in meaningful occupations. The model contains five components that address knowing and valuing oneself, making and meeting goals, communicating and dealing with conflict, and finally, learning from outcomes.

Occupational therapy interventions establish a clientcentered approach to facilitate engagement in meaningful occupations (15). These interventions help at-risk adolescents to develop self-understanding through reality-based treatment (16). Occupational therapists have the main role in transition services by preparing occupation-based evaluation and intervention (17). The primary focus of occupational therapists is occupations and activities related to school, relationships with friends and family, work, and socializing and creative activities (16). Creative activities provide meaning value and broad opportunities for choice and self-determination (18). Participating in activity can develop new skills in clients and promote learning through doing, which is one of the skills of occupational therapists (19). Despite these potentials in occupational therapy, there is a gap in self-determination-based transition planning programs to assist adolescents with or at risk of EBD.

However, some studies suggest that occupational therapy can be an appropriate intervention to promote self-determination (20-23), but there is limited evidence to examine the occupational therapy interventions in support of self-determination of the adolescent with or at risk of EBD. Therefore, the primary aim of this study was to determine the impact of occupational therapy interventions on the self-determination of adolescent girls at risk of EBD. The secondary aim of the research was to study the effects of OT interventions on parent's perception of the self-determination of their children.

\section{Methods}

\section{Study Design}

This single-blind (assessor) randomized controlled trial was designed in accordance with the CONSORT statement. Using block randomization, participant were assigned to the intervention and control groups. The ethical approval was obtained from the local ethical committee (9321525001IR.IUMS.REC.1396). The trial is registered with Clinical Trial Code (IRCT20171231038153N1). All participants provided informed consent and were free to withdraw at any stage. The setting for this study were classes of four public high schools.

\section{Participants}

Participants represent 54 high school age female students at risk of EBD selected by random cluster sampling from schools of North, South and Center of Tehran, Iran. The ages of the baseline participants 14 to 16 years old (mean age $=15.26 ; \mathrm{SD}=0.9)$. The participants studied in tenth $(n=38 ; 80.85 \%)$ and eleventh grade $(n=9 ; 19.15 \%)$ public high schools. The inclusion/ exclusion criteria were (a) age 14 to 16 , (b) scores 60 to 70 from the YSR (24), (c) written informed consent from the adolescents and their parents.

\section{Sample size and Randomization}

We calculated the sample size requirements per group based on a previous study and using the following formula $n=\frac{2}{d^{2}} \times C_{P . P o w e r}$, given a power of $80 \%$, a confidence interval of $95 \%$, and 0.87 mean differences. A sample size of 40 participants with 20 participants per group was required $(25,26)$. However, considering the attrition rate, 54 adolescents were randomly sampled for the intervention $(n=27)$ and control $(n=27)$ groups. Participants were randomized $1: 1$ into the intervention and control groups using the block randomization method (block size of 6). An independent person, who has not responsible elsewhere in the study, randomized codes by randomization block. Concealment of allocation was performed using sequentially numbered, sealed opaque envelopes. Figure 1 shows the recruitment and flow of participants throughout the trial.

\section{Procedure}

The study occurred during the academic year 2018-2019. At first, four girl high schools were randomly selected. The YSR conducted on 500 students, and 54 students at risk of EBD were included. Seven participants, after randomization, were deleted from the control group. They were reluctant to continue the research. All participants were assessed in pre- and post-intervention by a blinded assessor (master's degree in occupational therapy). The intervention program was implemented group-based. After completing the pretest (SDSS and SDPPS), according to Yalom and Leszcz's suggestion about the number of people in group therapy (27), the participants in the intervention group were divided into three groups (two groups of 10 and 1 group of 7 persons). The students in intervention groups received eight 90-min sessions of occupational therapy and a self-determination plan. At the start of the intervention, the participants received instructions about the intervention from the 


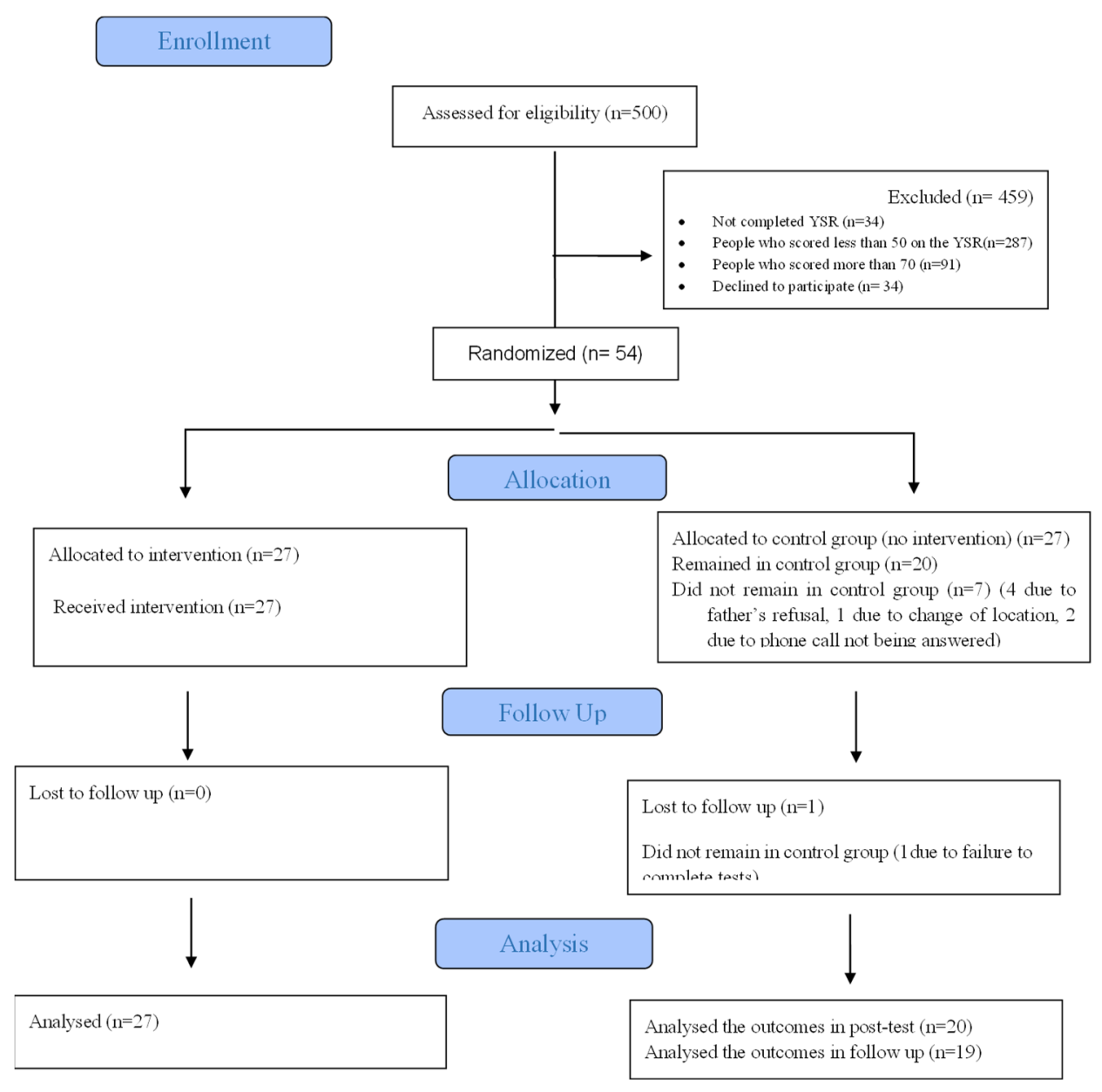

Fig. 1. CONSORT 2010 flow diagram of participants

researchers in the classroom. We set up a virtual group internet-based where the students of intervention groups to debate about their questions.

Our intervention program provided three consultation sessions to parents of the participant intervention. The sessions informed the parents about self-determination and the problems that are encountered the adolescents at risk of EBD. Each session lasted for one hour during the intervention plan for adolescents. The first session was held after the first intervention plan session. In that session, the concepts of self-determination were educated. An additional five sessions included parents of the intervention group discussing and reporting on the improvements in behavior by adolescents in self-determination.

The control group received no intervention. At the end of the study, the researcher provided comprehensive information back to the control group about the effects of the intervention in the form of a brochure, and she invited participants of the control group to receive a copy of the designed intervention free of charge.

Both groups were followed up after 10 weeks from posttest. The assessor conducted SDSS and SDPPS as a blind study of the intervention allocation.

\section{Youth Self-Report (YSR)}

The YSR has 112 items. It is a self-report questionnaire to assess the knowledge of adolescents (11 to 18 years old) about their emotional and behavioral function. The Items contain eight subscales, with two broad bands (Internalizing and Externalizing) and a Total Problems Scale. Participants responded to items using a 3-point Likert scale $(0=$ Not true, 1=Somewhat or Sometimes True, 2=Very True or Often True). Based on a previous research, the overall internal consistency of the YSR was good $(\alpha=0.95)(24)$. Minaei et al. adapted and standardized the psychometric properties of the Persian version of the YSR (28).

\section{Student Self-Determination Scale (SDSS)}

The SDSS measurement presented by Hoffman et al. in two self-report versions examined the cognitive and emotional dimensions of self-determination. The SDSS is a 92item self-report instrument. Students answer each item as "That's me" or "That's not me." One such item is: "I know what is important to me." Based on the Field and Hoffman self-determination model, the SDSS consists of five components namely "know- yourself" (16 items), "value- yourself" (16 items), "plan" (19 items), "act" (25 items), and "experience outcomes and learn" (16 items). This scale at 
the end provides a score for each component and one score for the total student self-determination. A higher score on the SDSS indicates higher self-determination ability. The estimated time of completion is between 30 to 50 minutes. Validity and reliability of SDSS were confirmed $(\alpha=0.91)$ (14). The Persian version of SDSS was prepared and confirmed in terms of psychometrics properties (29).

\section{Self-determination Parent Perception Scale (SDPPS)}

The SDPPS tool, which measures self-determination from a parent's perspective, is a 30 -item scale that asks parents to rate students on the five-point Likert scale $(1=$ low, $5=$ high) on various sections of the Field and Hoffman model (1994). Finally, five scores for each component, and by summing up the scores, the total score of the scale is obtained. The higher score in SDPPS shows a higher level of self-determination of the student from the parent's perspective. In the study of Hoffman et al., Cronbach's alpha coefficient was 0.95 (14), and the validity and reliability of the tool in the Iranian population have been verified by the authors (30).

\section{Intervention Program}

Before the intervention, a six-member expert panel was formed to decide how to implement the intervention program. The expert panel included four assistant professors and two Ph.D. students in occupational therapy who were skilled in adolescent mental health.

The intervention program was implemented in group sessions. The intervention was delivered and led by the first author. The author's role in the three groups of the intervention was leader, facilitator, and supporter. The intervention consisted of 8 sessions. Each 90-minute session occurred once a week with a rest time of 30 minutes between two forty-five minute sessions in one day. The sessions had two parts containing discussion and implementation of the activity.
At the start of a session, a description of the previous session was given to remind. The content of the discussion sections of the intervention was based on Field and Hoffman's Self-Determination Model (14). This model contains five components including: Know Yourself, Value Yourself, Plan, Act, and Experience Outcomes and Learn.

The activities were implemented along with components of self-determination in intervention sessions (Table 1). The group leader used specific therapeutic strategies derived from $\mathrm{MOHO}$ to interact and support students in intervention groups (31).

\section{Statistical analyses}

SPSS 16.0 software (SPSS, Inc., Chicago, IL, USA) was used for statistical analyses. For descriptive statistics, mean and standard deviation were used. Data were analyzed using the repeated measures general linear model (GLM), with three levels by time (pre, post, and follow up) and considering groups (intervention and control). Wilks' Lambda multivariate tests are reported to describe the effects of time analyzed. As the Mauchly's test of sphericity did not demonstrate the data homogeneity, the GreenhouseGeisser test was established . Furthermore, one-way analysis of variance (ANOVA), with a $95 \%$ confidence level and Bonferroni posthoc correction, were performed to detect between-group differences. In all statistical tests, the significance level was considered as $\mathrm{P}<0.05$.

\section{Results}

Forty-seven adolescents at risk of EBD after attrition (20 as a control and 27 as an intervention group) with the mean age of 15.26 months $(\mathrm{SD}=0.9)$ participated in this research. Demographics are presented in Table 2.

As shown in Table 3, the mean of student self-determination in the intervention group in the post-test (Mean= 154.30, $\mathrm{SD}=6.11)$ and follow-up $(\mathrm{Mean}=157.00, \mathrm{SD}=$ 13.49) has increased but in the control group the mean of student self-determination has decreased in the post-test

Table 1. Intervention Program

\begin{tabular}{|c|c|c|c|}
\hline Session & Subject of Discussion & Activity part & Goal \\
\hline 1 & $\begin{array}{l}\text { Expressing the dreams, weaknesses, } \\
\text { strengths, needs and preferences }\end{array}$ & $\begin{array}{l}\text { students write about their physical, mental, emotional and social } \\
\text { characteristics in pre-prepared forms, then talks about it and feed- } \\
\text { back to each other in the group. }\end{array}$ & $\begin{array}{l}\text { Know your- } \\
\text { self }\end{array}$ \\
\hline 2 & $\begin{array}{l}\text { Thinking about options, supports, expec- } \\
\text { tations and wishes to create opportuni- } \\
\text { ties }\end{array}$ & $\begin{array}{l}\text { Participants draw their dreams and express their desires and emo- } \\
\text { tions through conversation and using painting. }\end{array}$ & $\begin{array}{l}\text { Know your- } \\
\text { self }\end{array}$ \\
\hline 3 & $\begin{array}{l}\text { Identifying the importance and values of } \\
\text { life, objectify values }\end{array}$ & Using clay, they made symbolic products of their values & $\begin{array}{l}\text { Value your- } \\
\text { self }\end{array}$ \\
\hline 4 & $\begin{array}{l}\text { Creating opportunities to set long-term } \\
\text { goals, plan actions to meet goals }\end{array}$ & $\begin{array}{l}\text { They made a list of their long-term goals in different areas as a } \\
\text { collage by selecting pictures in magazines and newspapers and } \\
\text { pasting them into cardboard) }\end{array}$ & Plan \\
\hline 5 & Setting Short-Term goals & $\begin{array}{l}\text { They write short-term goal based on their long-term goal in the } \\
\text { pre-prepared forms and talk about whether their goals are realistic } \\
\text { and achievable }\end{array}$ & Plan \\
\hline 6 & $\begin{array}{l}\text { Practicing assertive skills and } \\
\text { Communication }\end{array}$ & $\begin{array}{l}\text { Role-playing about problems that they experience in communica- } \\
\text { tion skills in school or home, then help to each other to solve prob- } \\
\text { lems. }\end{array}$ & Act \\
\hline 7 & $\begin{array}{l}\text { Practice and act self-determined behav- } \\
\text { ior }\end{array}$ & $\begin{array}{l}\text { Cooking (preparing a meal and salad) . The students likened each } \\
\text { member of the group to a fruit or food based on their moral char- } \\
\text { acteristics and drew it. }\end{array}$ & Act \\
\hline 8 & Experiencing consequences and learning & $\begin{array}{l}\text { Arranging the environment and inviting guest (as a model of self- } \\
\text { determined person), making photographs, summarizing the results }\end{array}$ & $\begin{array}{l}\text { Experience } \\
\text { Outcomes } \\
\text { and Learn }\end{array}$ \\
\hline
\end{tabular}




\begin{tabular}{|c|c|c|c|c|c|}
\hline \multirow[t]{2}{*}{ Frequency } & & \multicolumn{2}{|c|}{ Intervention group } & \multicolumn{2}{|c|}{ Control group } \\
\hline & & $\mathrm{N}$ & $\%$ & $\mathrm{~N}$ & $\%$ \\
\hline \multirow[t]{2}{*}{ Age (year) } & $14-15$ & 19 & 70.37 & 17 & 85 \\
\hline & $15-16$ & 8 & 29.62 & 3 & 15 \\
\hline \multirow[t]{2}{*}{ Grade } & tenth & 20 & 74.07 & 18 & 90 \\
\hline & eleventh & 7 & 25.92 & 2 & 10 \\
\hline \multirow[t]{3}{*}{ Family status } & Living with parents & 24 & 88.88 & 15 & 75 \\
\hline & Living with mother & 0 & 0 & 1 & 5 \\
\hline & Living with father & 3 & 11.11 & 4 & 20 \\
\hline Family income & Less than 20 & 16 & 59.26 & 16 & 80 \\
\hline \multirow[t]{2}{*}{ (Millions of Iranian rials) } & Between 20 and 60 & 10 & 37.04 & 3 & 15 \\
\hline & More than 60 & 1 & 3.70 & 1 & 5 \\
\hline \multirow{4}{*}{ Mother's education } & illiterate & 5 & 18.52 & 4 & 20 \\
\hline & middle School & 5 & 18.52 & 6 & 30 \\
\hline & diploma & 14 & 51.85 & 9 & 45 \\
\hline & Bachelor & 3 & 11.11 & 1 & 5 \\
\hline \multirow[t]{4}{*}{ Father's education } & illiterate & 5 & 18.52 & 2 & 10 \\
\hline & middle School & 12 & 44.44 & 9 & 45 \\
\hline & diploma & 9 & 33.33 & 9 & 45 \\
\hline & Bachelor & 1 & 3.70 & 0 & 0 \\
\hline
\end{tabular}

Table 3. Descriptive statistics of student self-determination and parent perception of student self-determination in both intervention and control groups pre and post intervention and follow up

\begin{tabular}{lcccccc}
\hline & Groups & \multicolumn{2}{c}{ Pre-test } & \multicolumn{2}{c}{ Post-test } \\
\cline { 2 - 6 } & & Mean & SD & Mean & SD & Mean \\
\cline { 2 - 6 } Student self-determination & Intervention & 143.70 & 11.89 & 154.30 & 6.11 & 157.00 \\
& Control & 146.00 & 10.01 & 141.63 & 10.48 & 140.95 \\
Parent perception of student & Intervention & 72.56 & 16.15 & 83.56 & 7.34 & 82.26 \\
self-determination & Control & 74.05 & 17.61 & 72.42 & 17.18 & 71.79 \\
\hline
\end{tabular}

$(\mathrm{Mean}=141.63, \mathrm{SD}=10.48)$ and follow-up $(\mathrm{Mean}=140.95$, $\mathrm{SD}=9.24)$ compared to the pre-test. Also, the mean of parent perception of student self-determination in the intervention group has increased at the post-test (Mean $=83.56$, $\mathrm{SD}=7.34$ ) but at the follow-up (Mean=82.26, $\mathrm{SD}=8.28$ ) has decreased. The mean of parent perception of student selfdetermination in the control group at the post-test (Mean=72.42, $\mathrm{SD}=17.18$ ) and at follow up (Mean=71.79, $\mathrm{SD}=16.05$ ) has decreased.

A repeated-measures ANOVA with a mix of one within group effect for time (Pretest, Posttest, and Follow up) and one between group effect (intervention and control) was conducted to compare the effect of occupational therapy on student self-determination and parent perception of student self-determination. In student self-determination, the Wilks' Lambda multivariate test of overall differences among groups was statistically significant for time (Wilks'
Lambda $=0.827,, \mathrm{p}=0.017$ ) and for time * group (Wilks' Lambda $=0.466, \mathrm{p}<0.001)$ In the parent perception of student self-determination, the Wilks lambda multivariate test of overall differences between intervention and control groups was statistically significant for time (Wilks' Lambda $=0.810, \mathrm{p}=0.011$ ) and for time * group (Wilks' Lambda $=0.840 \mathrm{P}=0.024)$. Thus, it can be concluded that the occupational therapy interventions has been effective on student self-determination (Fig. 2) and parent perception of self-determination (Fig. 3) during the time and between the two groups.

determination and parent perception $(p<0.05)$, the degrees of freedom were corrected using the epsilon obtained through the Greenhouse-Geisser procedure. The result of a repeated measures ANOVA with a Greenhouse-Geisser correction detected that the effect of intervention on student self-determination has been significant for time $(\mathrm{p}=0.040)$,

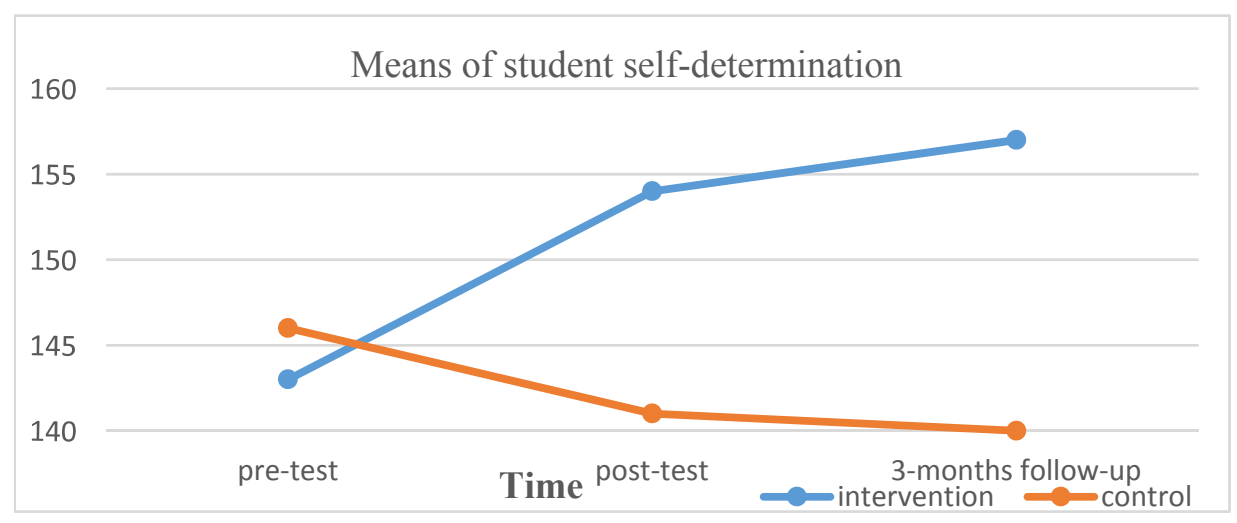

Fig. 2. Means of student self-determination assessed at pre-test, post-test, and 3-months follow-up 


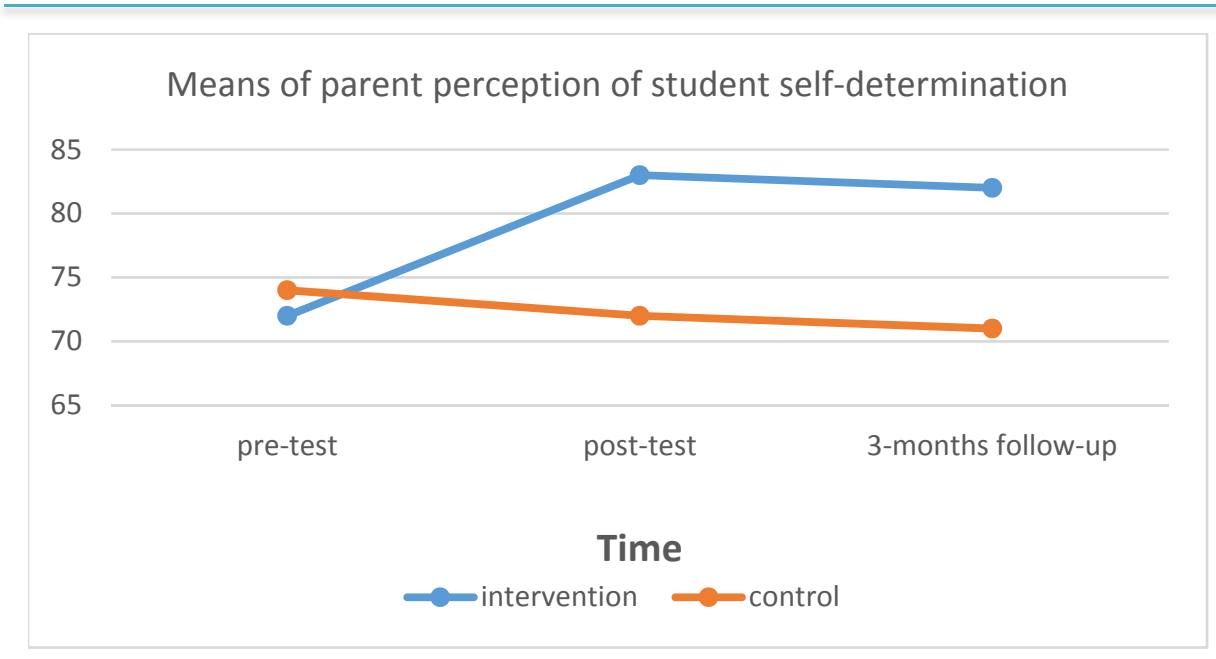

Fig. 3. Means of parent perception of student self-determination assessed at pre-test, post-test, and 3-months follow-up.

and for time $*$ group $(\mathrm{p}<0.001)$.

Furthermore, a repeated measures ANOVA with a Greenhouse-Geisser correction, showed that the effect of intervention on parent perception of self-determination has been significant during the time $(p=0.032)$, and for time * group ( $\mathrm{p}=0.002)$. Table 4 shows the results of the Tests of Within-Subjects Effects.
According to Table 5, the results showed that the effect of intervention between groups in student self-determination was statistically different $(\mathrm{p}<0.001)$. Figure 2 shows that the intervention had an increasing effect in the intervention group, but self-determination decreases through time in the control group; although no significance differ-

Table 4. Tests of Within-Subjects Effects of student self-determination and parent perception

\begin{tabular}{|c|c|c|c|c|c|c|c|}
\hline & Source & & Mean square & $\mathrm{df}$ & $F$ & $\mathrm{P}$-value & $\begin{array}{c}\text { Partial Eta } \\
\text { Squared }\end{array}$ \\
\hline \multirow{8}{*}{ } & Time & Sphericity Assumed & 411.800 & 2 & 3.629 & 0.031 & 0.076 \\
\hline & & Greenhouse-Geisser & 411.800 & 1.618 & 3.629 & 0.040 & 0.076 \\
\hline & & Huynh-Feldt & 411.800 & 1.709 & 3.629 & 0.038 & 0.076 \\
\hline & & Lower-bound & 411.800 & 1.000 & 3.629 & 0.063 & 0.076 \\
\hline & Time* & Sphericity Assumed & 2126.322 & 2 & 18.738 & $<0.001$ & 0.299 \\
\hline & group & Greenhouse-Geisser & 2126.322 & 1.618 & 18.738 & $<0.001$ & 0.299 \\
\hline & & Huynh-Feldt & 2126.322 & 1.709 & 18.738 & $<0.001$ & 0.299 \\
\hline & & Lower-bound & 2126.322 & 1.000 & 18.738 & $<0.001$ & 0.299 \\
\hline \multirow{16}{*}{ 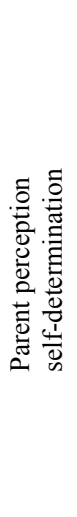 } & Error & Sphericity Assumed & 56.740 & 88 & & & \\
\hline & & Greenhouse-Geisser & 70.127 & 71.20 & & & \\
\hline & & Huynh-Feldt & 66.395 & 75.20 & & & \\
\hline & & Lower-bound & 113.479 & 44.00 & & & \\
\hline & Time & Sphericity Assumed & 272.942 & 2 & 4.735 & 0.011 & 0.097 \\
\hline & & Greenhouse-Geisser & 503.739 & 1.084 & 4.735 & 0.032 & 0.097 \\
\hline & & Huynh-Feldt & 489.614 & 1.115 & 4.735 & 0.031 & 0.097 \\
\hline & & Lower-bound & 545.883 & 1.000 & 4.735 & 0.035 & 0.097 \\
\hline & Time* & Sphericity Assumed & 563.565 & 2 & 9.777 & $<0.001$ & 0.182 \\
\hline & group & Greenhouse-Geisser & 1040.110 & 1.084 & 9.777 & 0.002 & 0.182 \\
\hline & & Huynh-Feldt & 1010.946 & 1.115 & 9.777 & 0.002 & 0.182 \\
\hline & & Lower-bound & 1127.129 & 1.000 & 9.777 & 0.003 & 0.182 \\
\hline & Error & Sphericity Assumed & 57.643 & 88 & & & \\
\hline & & Greenhouse-Geisser & 106.386 & 47.681 & & & \\
\hline & & Huynh-Feldt & 103.403 & 49.057 & & & \\
\hline & & Lower-bound & 115.286 & 44.000 & & & \\
\hline
\end{tabular}

Table 5. Tests of Between-Subjects Effects of student self-determination and parent perception

\begin{tabular}{cccccc} 
Source & Mean square & df & F & P-value & Partial Eta Squared \\
\hline Intercept & 2902211.094 & 1 & 13140.90 & $<0.001$ & .997 \\
Group & 2595.007 & 1 & 11.750 & .001 & .211 \\
Error & 220.853 & 44 & & & .974 \\
Intercept & 775128.796 & 1 & 1668.521 & $<0.001$ & .068 \\
Group & 1502.941 & 1 & 3.235 & .079 & \\
Error & 464.560 & 44 & & &
\end{tabular}


Table 6. Post Hoc Bonferroni adjusted pairwise comparisons of student self-determination and parent perception of self-determination at pre-test, post-test and 3-months follow up

\begin{tabular}{lccc}
\hline Dependent Variable & Measurement Time & Mean Difference & Standard Deviation \\
\hline Student self-determination & Pretest-Posttest & -3.11 & 1.14 \\
& Pretest- Follow up & -4.12 & 1.81 \\
& Posttest- Follow up & -1.01 & 1.74 \\
Parent perception of self- & Pretest-Posttest & -4.68 & 1.96 \\
determination & Pretest- Follow up & -3.72 & 1.000 \\
& Posttest- Follow up & 0.96 & 0.064 \\
\hline
\end{tabular}

ence was found in parent perception of student self-determination $(\mathrm{p}=0.079)$. The Figure 3 also indicates these results.

The results of the Bonferroni post hoc test in Table 6 revealed that there was a significant difference in student selfdetermination between pretest-posttest $(\mathrm{p}<0.001)$, but no significant difference between posttest and 3-month follow up $(p>0.05)$. Further results also indicate that there were no significant differences in parent perception of self-determination between pretest-posttest and posttest- follow-up $(\mathrm{p}>0.05)$.

\section{Discussion}

The current study examined the effect of occupational therapy interventions based on MOHO and Field and Hoffman self-determination model on self-determination of adolescents at risk of EBD. The intervention group's results indicated that occupational therapy has a positive effect on student self-determination compared to the control group. Furthermore, comparing the pretest, posttest and follow-up scores revealed that self-determination has increased for participants of the intervention group. Although the mean scores of parent perception of student self-determination have increased from pretest to posttest; we found no significant differences. These findings supported the hypothesis that occupational therapy interventions could be strengthen self-determination among adolescents at risk of EBD.

Similar results has also been obtained by Juan et al., stating that occupational therapists can provide a meaningful, client-centered transition process on increasing self-determination (17). The research by Gregitis et al. proved that establishing an Occupation-Based Self-Determination program for EBD students could foster self-determination skills (23). Angell et al. determined occupational therapy is an appropriate support for students with disabilities to have self-determined behavior during adolescence to adulthood (19).

A part of the study focused on holding consultation sessions for the parents of the intervention groups. The improvement of mean scores of parent's perception about their adolescent self-determination at pretest-posttest (Table 5) occurred, but by the end of the intervention and at 3months follow up, the mean scores have decreased. It could be concluded that the parents became more aware of the dreams, strengths, weaknesses of their children during the intervention, but perhaps the number of sessions was not enough, or the need for parents of students with EBD to counseling may remain during the adolescence. Field and Hoffman suggested that parents attend with their adolescents and perform activities with each other in sessions (32). It seems that this method causes students to interact more with their parents and can be useful in the parent perception towards the student self-determination.

The achieved experience gained in the present study also showed that parental support and encouragement of adolescents could increase the students' willingness to engage in activities. Previous research has found that family support is important in adolescence $(33,34)$. It seemed that adolescents who were repressed and humiliated by their families, some of the disturbing thoughts toward their parents emerged during the projective activities in the intervention sessions; as a result, they hesitated to finish the activities that required creativity such as pottery or paintings and they were trying to abandon the practice.

Most adolescents participating in this project at the beginning of intervention sessions were impulsive and unfamiliar about their future and goals and were also uninformed and reluctant about their self-awareness and values. During the occupational therapy interventions based on $\mathrm{MOHO}$ concepts, they were able to increase the awareness of their interests, values, abilities, weaknesses, and performance capacity and adapt themselves to the living environment, which enhanced their motivation for future choices. The authors believe that considering the concept of $\mathrm{MOHO}$ can help to develop and structure the occupation-based interventions. This belief has been confirmed in previous studies (35-37).

\section{Conclusion}

The findings of this study indicated that occupational therapy interventions might be beneficial and effective for adolescents at risk of EBD to develop self-determination skills. Thus, by increasing self-awareness and self-esteem can prevent of possible future harms. Considering the findings of the present study on the role of occupational therapy interventions to enhance self-determination skills and the importance of the preventive role in adolescents at risk of EBD, it seems to be a need for further work in both clinical and research contexts.

\section{Study limitations}

It is suggested that future research can determine the effect of the present study's interventions with a range of other factors such as different ethnicity, gender, and adolescence ages since only adolescent girls at risk of EBD were examined in this study. Since students in this study couldn't attend sessions on two days of the week, the sessions were held in a day of the week with a longer time $(90$ min). It is suggested to implement the intervention sessions (45 min) in two days per week for future research. The intervention program of the present study can also be implemented individually by considering the conditions and 
characteristics of the adolescent and the family, their needs and priorities regarding the environment and context of adolescent life. Another suggestion for future research is to administer this study in EBD adolescents with their parents and teachers. Since the importance of self-determination has been identified in adolescent transition, it is recommended that occupational therapists consider self-determination in topics of future research.

\section{Acknowledgements}

The authors would like to acknowledge the student participants, staff at the schools, and the parents who participated in this study. This article represents a portion of the first authored as part of a doctoral dissertation at the School of Rehabilitation, Iran University of Medical Sciences, Tehran, Iran.

\section{Conflict of Interests}

The authors declare that they have no competing interests.

\section{References}

1. Das JK, Salam RA, Lassi ZS, Khan MN, Mahmood W, Patel V, et al. Interventions for adolescent mental health: an overview of systematic reviews. J Adolesc Health. 2016;59(4):S49-S60.

2. Farmer TW, Hamm JV, Petrin RA, Robertson D, Murray RA, Meece JL, et al. Supporting early adolescent learning and social strengths: Promoting productive contexts for students at-risk for EBD during the transition to middle school. Exceptionality. 2010;18(2):94-106.

3. George HP. Introduction to the special issue of behavioral disorders: positive behavior interventions and supports. Behav Disord. 2018;43(3):340-3.

4. Kelly JR, Shogren KA. The impact of teaching self-determination skills on the on-task and off-task behaviors of students with emotional and behavioral disorders. J Emot Behav Disord. 2014;22(1):27-40.

5. Black RS, Leake D. Teachers' Views of Self-Determination for Students with Emotional/Behavioral Disorders: The Limitations of an Individualistic Perspective. Int J Spec Educ. 2011;26(1):147-61.

6. Chambers AC. Application of the choicemaker curriculum for teaching self-determination skills to students with emotional and behavioral disabilities in a private day setting: The George Washington University; 2010.

7. Wehmeyer ML, Palmer SB, Shogren K, Williams-Diehm K, Soukup $\mathrm{JH}$. Establishing a causal relationship between intervention to promote self-determination and enhanced student self-determination. J Spec Educ. 2013;46(4)195-210.

8. Shogren KA, Wehmeyer ML, Lane KL. Embedding interventions to promote self-determination within multitiered systems of supports. Exceptionality. 2016;24(4):213-24.

9. Fleming-Castaldy RP, Bauck Horning J. It's MY Life: A Student's Perceptions of Her Individualized Transition Program. J Occup Ther Sch Early Interv. 2013;6(3):269-87.

10. Berg C, King A, Edwards DF. Mentoring Program for Young Adults with Sickle Cell Disease. Occup Ther Health Care. 2018;32(2)124-36.

11. Lindsay S, Lamptey D-L, Cagliostro E, Srikanthan D, Mortaji N, Karon L. A systematic review of post-secondary transition interventions for youth with disabilities. Disabil Rehabil. 2019;41(21):2492-505.

12. Mansurnejad Z, Malekpour M, Ghamarani A, Yarmmohamadiyan A. The effects of teaching self-determination skills on the externalizing behaviors of students with emotional behavioral disorders. Emot Behav Diffic. 2019:1-8.

13. Zirkus KJ, Morgan JJ. Enhancing self-determination skills for students with emotional and behavioral disorders. Interv Sch Clin. 2020;55(4):238-44.

14. Hoffman A, Field S, Sawilowsky S. Self-Determination Assessment Battery. User's guide. Center for Self-Determination and Transition: Promoting Resiliency and Well-being Throughout the Lifespan College of Education, Wayne State University Retrieved May. 2004;6:2008.
15. Kreider CM, Bendixen RM, Huang YY, Lim Y. Review of occupational therapy intervention research in the practice area of children and youth 2009-2013. Am J Occup Ther. 2014;68(2):e61-e73.

16. Cara E, MacRae A. Psychosocial occupational therapy: An evolving practice: Nelson Education; 2012.

17. Juan HG, Swinth Y. As students become adults: The role of occupational therapy in the transition process. J Occup Ther Sch Early Interv. 2010;3(3):255-67.

18. Griffiths $\mathrm{S}$. The experience of creative activity as a treatment medium. J Ment Health. 2008;17(1):49-63.

19. Angell AM, Carroll TC, Bagatell N, Chen C, Kramer JM, Schwartz $\mathrm{A}$, et al. Understanding self-determination as a crucial component in promoting the distinct value of occupational therapy in post-secondary transition planning. J Occup Ther Sch Early Interv. 2019;12(1):129-43.

20. Dunn L, Thrall L. Development of self-determination across childhood and adolescence. J Occup Ther Sch Early Interv. 2012;5(2):165-81.

21. Miller, Elizabeth Kelly, "Occupational Therapists' Intervention Approaches in Secondary Transition Services for Students with Disabilities" (2012). Online Theses and Dissertations. 83.

22. Dean EE, Dunn W, Tomchek S. Role of occupational therapy in promoting self-determination through consumer-directed supports Occup Ther Health Care. 2015;29(1):86-95.

23. Gregitis S, Gelpi T, Moore B, Dees M. Self-determination skills of adolescents enrolled in special education: an analysis of four cases. Occup Ther Ment Health. 2010;26(1):67-84

24. Achenbach T, Rescorla L. Manual for the ASEBA school-age forms \& profiles: an integrated system of multi-informant assessment Burlington, VT: University of Vermont. Research Center for Children, Youth, \& Families. 2001;1617.

25. Whitley E, Ball J. Statistics review 4: Sample size calculations. Critical Care. 2002;6(4):335.

26. Cuevas R, García-López LM, Serra-Olivares J. Sport education model and self-determination theory: An intervention in secondary school children. Kinesiol Int J Fundam Appl Kinesiol. 2016;48(1):30-8.

27. Cole MB. Group dynamics in occupational therapy: the theoretical basis and practice application of group intervention. 4, editor. SLACK Inc: Thorofare, $\mathrm{NJ} ; 2012$

28. Minaei A. Adaptation and standardization of child behavior checklist, youth self-report, and teacher's report forms. 2006.

29. Hojati Abed E, Shafaroudi N, Akbarfahimi M, Zareian A, Parand A, Karamali Esmaili S. Persian Translation and Psychometric Properties Assessment of Self-Determination Student Scale for Adolescents. Archives of Rehabilitation. 2019;20(4):350-9.

30. Hojati Abed E, Akbarfahimi M, Shafaroudi N, Zareian A, Parand A, Karamali Esmaieli S. Psychometric Properties of the Persian Version of Self-determination Parent Perception Scale. Iran Rehabil J. 2020;18(1):23-30.

31. Kielhofner G. The basic concepts of human occupation. Model of human occupation: Theory and application. 2008:11-23.

32. Field S, Hoffman A. The importance of family involvement for promoting self-determination in adolescents with autism and other developmental disabilities. Focus Autism Other Dev. Disabil.1999;14(1):36-41.

33. Van Harmelen A-L, Gibson JL, St Clair MC, Owens M, Brodbeck J, Dunn V, et al. Friendships and family support reduce subsequent depressive symptoms in at-risk adolescents. PloS one. 2016.

34. Matlin SL, Molock SD, Tebes JK. Suicidality and depression among African American adolescents: The role of family and peer support and community connectedness. Am J Orthopsychiatry. 2011;81(1):108.

35. Esmaili SK, Mehraban AH, Shafaroodi N, Yazdani F, Masoumi T, Zarei M. Participation in Peer-Play Activities Among Children With Specific Learning Disability: A Randomized Controlled Trial. Am J Occup Ther. 2019;73(2):7302205110p1-p9.

36. Shinohara K, Yamada T, Kobayashi N, Forsyth K. The model of human occupation-based intervention for patients with stroke: A randomised trial. Hong Kong J. Occup. Ther. 2012;22(2):60-9.

37. Lee J. Achieving best practice: A review of evidence linked to occupation-focused practice models. Occup Ther Health Care. 2010;24(3):206-22. 